Bull. Egypt. Soc. Physiol. Sci. Vol. (41) Issue (3), 283-295

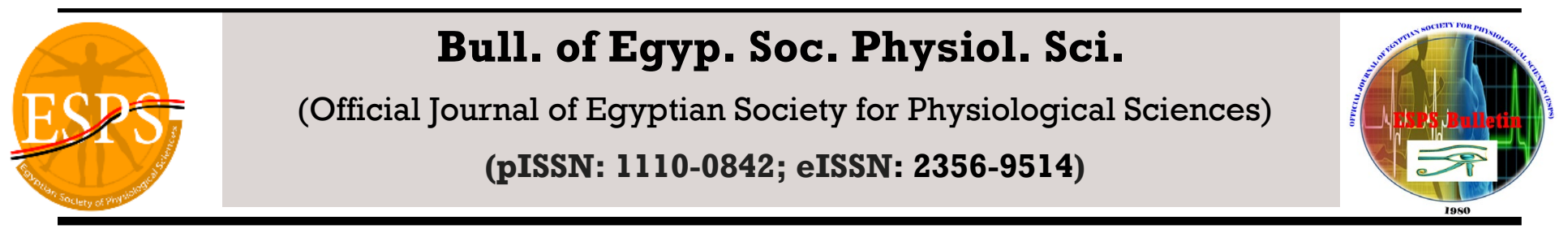

\title{
Effect of Different Acute Exercise Intensities on the Inflammatory Markers in Overweight and Obese Subjects
}

\author{
Mamdouh M. El-Yamany ${ }^{1}$, Samia Elewa ${ }^{1}$, Eman Y. Khairy ${ }^{1}$, Ola A. Salama ${ }^{1}$, Noha S. Kandil ${ }^{2}$, Mona \\ Sherif ${ }^{1}$ \\ ${ }^{1}$ Department of Physiology, Medical Research Institute, University of Alexandria, Egypt. \\ ${ }^{2}$ Department of Chemical Pathology, Medical Research Institute, University of Alexandria, Egypt.
}

Submit Date: July 21, 2020

Accept Date: Sept 25, 2020

Available Online: Jan 15,2021

\section{Keywords}

- Exercise

- Obesity

- CRP

- $\quad$ IL-6

- TNF- $\alpha$

\section{Abstract}

The aim of this work was to investigate the effect of an acute bout of different exercise intensities on modifying the inflammatory markers in overweight and obese subjects. Sixty adult males divided into: a control group $(n=30)$ included normal weight subjects $\left(\mathrm{BMI}<25 \mathrm{~kg} / \mathrm{m}^{2}\right)$ and an overweight (OW) and obese group $(\mathrm{n}=30)$ included subjects with $\mathrm{BMI} \geq 25 \mathrm{~kg} / \mathrm{m}^{2}$. Each group was randomly subdivided into three groups $(\mathrm{n}=10$ each): low, moderate and high intensity exercise groups. Anthropometric measurements obtained and plasma C-reactive protein (CRP), interleukin-6 (IL-6) and tumor necrosis factor alpha (TNF- $\alpha$ ) levels were measured before and thirty minutes after twenty minutes incremental exercise, at $45 \%, 60 \%$ or $80 \%$ of predicted maximum heart rate, on a motor driven treadmill. Following an acute bout of moderate or high intensity exercise, OW and obese subjects showed significant increase in CRP and IL-6 levels; however, TNF- $\alpha$ levels significantly decreased. Nevertheless, an acute low intensity exercise induced no significant changes in any of the measured markers in the OW and obese subjects. In conclusion, an acute bout of moderate or high intensity exercise, but not low intensity exercise, induces an inflammatory response, characterized by a rise in levels of CRP and IL-6, and a decrease in TNF- $\alpha$ level in overweight and obese subjects.

Corresponding author: Eman Y. Khairy. Department of Physiology, Medical Research Institute, Alexandria University, Egypt. E-mail address: eman23475@yahoo.com 


\section{INTRODUCTION}

The prevalence of obesity has increased in recent years. Around 1.9 billion adults are overweight worldwide, of which over 600 million individuals are obese [1].

Obesity is associated with chronic low-grade inflammation characterized by increase in systemic circulating levels of inflammatory markers such as C-reactive protein (CRP) and the proinflammatory cytokines tumor necrosis factor alpha (TNF- $\alpha$ ) and interleukin-6 (IL-6) [2]. This has been implicated in the interplay between obesity and metabolic complications, including type 2 diabetes, atherosclerosis and cardiovascular disease $[3,4]$. However, studies reported that this state of low grade inflammation seems to be reversible via weight loss achieved through dietary intervention alone or diet and exercise [5,6].

Physical activity, with or without weight loss, has significant beneficial effects on cardiovascular and metabolic risk factors. It modulates immune function, improves plasma lipoprotein status particularly increasing high density lipoproteins and therefore may be of benefit to obese individuals [7].

The effect of exercise on inflammatory markers has been the subject of many studies; however, results have been somehow inconsistent. A number of studies reported that participation in regular exercise can reduce basal or resting levels of many inflammatory markers including CRP, TNF- $\alpha$ and IL-6 and thus could protect against diseases associated with chronic low-grade systemic inflammation [8,9]. However, other studies reported no change in either TNF- $\alpha$ [10] or IL-6
[11] levels after 12 weeks of moderate-intensity exercise training.

It has been hypothesized that the long-term effect of exercise and the protection against diseases associated with chronic low-grade inflammation may be ascribed to the antiinflammatory response elicited by each bout of acute exercise [12]. Nevertheless, studies investigating the effect of acute exercise on inflammatory markers have provided conflicting results [13-16].

IL-6 has been reported as the earliest and most marked post-exercise inflammatory respondent $[13,15,16]$. Some studies reported a significant increase in circulating TNF- $\alpha$ [16] and CRP [15] levels after acute bouts of moderate intensity exercise, while other studies found no change in TNF- $\alpha$ [13] or CRP [14] levels.

Exercise can be used as an adjuvant in treatment of inflammatory and non-inflammatory diseases [17]. Thus, understanding the acute inflammatory response to exercise may assist with appropriate exercise prescription and avoidance of undesirable consequences. Due to the inconsistency in literature about the inflammatory response to an acute bout of exercise, hence, the aim of this work was to investigate the effect of an acute bout of different exercise intensities on modifying the inflammatory markers in overweight and obese subjects.

\section{Materials and methods}

\section{Participants}

Sixty adult male subjects participated in this study. They were divided according to their body mass index (BMI) into: a control group $(n=30)$ included normal weight subjects with $\mathrm{BMI}<25$ $\mathrm{kg} / \mathrm{m}^{2}(20.54 \pm 2.10)$ and an overweight (OW) and 
obese group $(n=30)$ included subjects whose BMI was $\geq 25 \mathrm{~kg} / \mathrm{m}^{2}(33.34 \pm 4.23)$. Each group was randomly subdivided into three exercise groups $(\mathrm{n}=10$ each): low, moderate and high intensity exercise groups; each exercise group included ten subjects with $\mathrm{BMI} \geq 25 \mathrm{~kg} / \mathrm{m}^{2}$ and ten normal weight subjects with BMI $<25 \mathrm{~kg} / \mathrm{m}^{2}$. All participants have been weight stable $( \pm 2 \mathrm{~kg})$ for at least two weeks before the study and didn't engage in any regular physical activity or exercise training (sedentary to lightly active lifestyle). Exclusion criteria were cardiovascular disease, diabetes, or orthopedic difficulties causing inability to perform the required exercise. No subjects received medication that could affect the investigated markers. Prior to participation, the subjects gave a written informed consent according to the ethical guidelines of the Medical Research Institute, Alexandria University, Egypt.

\section{Methods}

\section{Anthropometric measurements}

Current body weight was measured. Height was measured with a standing stadiometer and recorded with a precision of $0.1 \mathrm{~cm}$. BMI was calculated using the standard formula: body weight in kilograms divided by height in meters squared $\left(\mathrm{kg} / \mathrm{m}^{2}\right)$ [18]. Waist circumference was measured, as recommended by the WHO, as the circumference line half way between the lowest costal margin and the iliac crest [18]. Anthropometric data of the subjects in different groups are presented in table (1).

Table (1): Anthropometric data of control and overweight (OW) \& obese subjects in different groups of exercise intensity.

\begin{tabular}{|c|c|c|c|c|}
\hline & Total & Low intensity exercise & Moderate intensity exercise & High intensity exercise \\
\hline & $\begin{array}{cc}\begin{array}{c}\text { Control } \\
(n=30)\end{array} & \text { OW \& obese } \\
(n=30)\end{array}$ & $\begin{array}{c}\text { OW \& obese } \\
(n=10)\end{array}$ & $\begin{array}{c}\text { OW\& obese } \\
(n=10)\end{array}$ & $\begin{array}{c}\text { OW \& obese } \\
(n=10)\end{array}$ \\
\hline \multicolumn{5}{|l|}{ Age (Years) } \\
\hline Mean \pm SEM. & $29.73 \pm 1.71 \quad 30.67 \pm 1.85$ & $30.0 \pm 3.15 \quad 26.30 \pm 2.30$ & $32.90 \pm 4.0$ & $29.40 \pm 3.24 \quad 32.80 \pm 2.94$ \\
\hline Sig. bet. groups (p) & 0.712 & 0.355 & 0.532 & 0.447 \\
\hline Weight $(\mathrm{Kg})$ & & & & \\
\hline Mean \pm SEM. & $63.27 \pm 1.49 \quad 100.13 \pm 2.48$ & $60.30 \pm 1.40 \quad 104.90 \pm 5.21$ & $63.60 \pm 2.30 \quad 100.10 \pm 4.40$ & $65.90 \pm 3.52 \quad 95.40 \pm 2.48$ \\
\hline Sig. bet. groups (p) & $<0.001^{*}$ & $<0.001^{*}$ & $<0.001^{*}$ & $<0.001^{*}$ \\
\hline Height (m) & & & & \\
\hline Mean \pm SEM. & $1.75 \pm 0.01 \quad 1.73 \pm 0.01$ & $1.77 \pm 0.03$ & $1.75 \pm 0.02$ & $1.73 \pm 0.02$ \\
\hline $\begin{array}{l}\text { Sig. bet. groups (p) } \\
\text { BMI }\left(\mathrm{Kg} / \mathrm{m}^{2}\right)\end{array}$ & 0.215 & 0.270 & 0.701 & 0.641 \\
\hline Mean \pm SEM. & $20.54 \pm 0.38 \quad 33.34 \pm 0.77$ & $19.23 \pm 0.31 \quad 34.92 \pm 1.49$ & $20.93 \pm 0.82 \quad 33.24 \pm 1.37$ & $21.45 \pm 0.59 \quad 31.86 \pm 1.06$ \\
\hline $\begin{array}{l}\text { Sig. bet. groups }(\mathrm{p}) \\
\text { Waist circum. }(\mathrm{cm})\end{array}$ & $<0.001^{*}$ & $<0.001^{*}$ & $\begin{array}{r}20.75+0.02 \\
<0.001^{*}\end{array}$ & $<0.001^{*}$ \\
\hline Mean \pm SEM & $79.13 \pm 1.20 \quad 108.63 \pm 1.74$ & $77.90 \pm 1.31 \quad 108.70 \pm 3.26$ & $79.50 \pm 2.71 \quad 111.10 \pm 3.38$ & $80.0 \pm 2.14 \quad 106.10 \pm 2.41$ \\
\hline Sig. bet. groups (p) & $<0.001^{*}$ & $<0.001^{*}$ & $<0.001^{*}$ & $<0.001^{*}$ \\
\hline
\end{tabular}

Note: $p, p$ value for Student t-test for comparing between cases and control in each subgroup; SEM, standard error of mean; *: Statistically significant at $\mathrm{p} \leq 0.05$.

\section{Exercise protocol}

Participants performed one session of twenty minutes incremental exercise test of low, moderate or high intensity (at $45 \%, 60 \%$ and $80 \%$ of their age predicted maximum heart rate, respectively) on a motor driven treadmill with adjustable speed and grade and equipped with a heart rate sensor. The age predicted maximum heart rate was calculated using the equation: HRmax $=220-$ age [19]. The test started with a 5-min warm-up, during which speed was gradually increased at a rate of $1 \mathrm{~km} / \mathrm{h}$ each minute, until a starting speed of 
$5.3 \mathrm{~km} / \mathrm{h}$ was reached, at which point the twenty minutes exercise session was started, based on the Balke protocol [20], starting with an incline of $0 \%$ and a speed of $5.3 \mathrm{~km} / \mathrm{h}(3.3 \mathrm{mph})$, the incline was then increased to $2 \%$ after one minute, then increased by $1 \%$ each minute thereafter until target heart rate was reached. Participants continued to run until the end of the twenty minutes period. Incline was reduced to 0 and speed to $3 \mathrm{~km} / \mathrm{h}$ and participants continued to run for another two minutes as a recovery period. For some participants with low cardiorespiratory fitness, the target heart rate was reached during the warm up period, hence the speed and incline couldn't be increased any further.

\section{Blood sampling and analysis}

Blood samples $(5 \mathrm{ml})$ were collected by venipuncture immediately before exercise and thirty minutes after termination of exercise. The serum was separated and frozen at $-20{ }^{\circ} \mathrm{C}$ for later analysis. Serum CRP, IL-6 and TNF- $\alpha$ levels were measured using commercially available enzymelinked immunosorbent assay (ELISA) kits (human Hs-CRP ELISA kit (Immunospec, USA), human IL-6 ELISA kit (eBioscience, Austria) and human TNF- $\alpha$ ELISA kit (eBioscience, Austria), respectively), according to the manufacturer's instructions [21].

\section{Statistical analysis}

Statistical analysis was performed using IBM SPSS software package version 20.0. Kolmogorov-Smirnov test was used to determine the normality of distribution and revealed that most of the data were non-normally distributed. Non-normally distributed quantitative data were described using range (minimum and maximum) and median. However, mean and standard deviation were used to describe normally distributed quantitative data. Student t-test was used for comparing normally distributed quantitative variables between two studied groups. Mann Whitney test was used for comparing nonnormally distributed quantitative variables between two studied groups. Wilcoxon signed ranks test was used for comparing non-normally distributed quantitative variables between two periods (baseline and after exercise). KruskalWallis test was used for comparing non-normally distributed quantitative variables between three groups. Correlations between measured parameters were assessed by Spearman's correlation. The level of significance was set at $\mathrm{P}<0.05$.

\section{Results}

CRP level was significantly higher in OW and obese subjects when compared with control subjects in the total group and in the different subgroups of exercise intensity, before and after exercise. CRP levels increased significantly after exercise in the total OW and obese group, as well as in the moderate and high intensity exercise subgroups (table 2). The percent of change in CRP level increased significantly with increasing exercise intensity from low to high intensity in the OW and obese subjects $(p=0.009)$. There was, however, no significant difference in the percent of change in CRP levels between the different subgroups of exercise intensity in the control subjects (table 5).

IL-6 level was significantly higher in the OW and obese subjects when compared with the control subjects in the total group and in the different subgroups of exercise intensity, before and after exercise. IL-6 level significantly increased after exercise, when compared with 
before exercise, in the OW and obese subjects in the total group and in the moderate and high intensity exercise subgroups, but not in the low intensity exercise subgroup (table 3). The percent of change in IL-6 level increased significantly with increasing exercise intensity from low to high intensity $(\mathrm{p}=0.007)$ and from moderate to high intensity ( $\mathrm{p}=0.017)$ in the OW and obese subjects. There was, however, no significant difference in the percent of change in IL-6 levels between the different subgroups of exercise intensity in the control subjects (table 5).

Table (2): C-reactive protein (CRP) level in control and overweight (OW) \& obese subjects in different groups of exercise intensity

\begin{tabular}{|c|c|c|c|c|c|c|c|c|}
\hline \multirow[b]{2}{*}{ CRP } & \multicolumn{2}{|c|}{ Total } & \multicolumn{2}{|c|}{ Low intensity exercise } & \multicolumn{2}{|c|}{ Moderate intensity exercise } & \multicolumn{2}{|c|}{ High intensity exercise } \\
\hline & $\begin{array}{c}\text { Control } \\
(\mathrm{n}=30)\end{array}$ & $\begin{array}{c}\begin{array}{c}\text { OW \& obese } \\
(n=30)\end{array} \\
\end{array}$ & $\begin{array}{c}\text { Control } \\
(n=10)\end{array}$ & $\begin{array}{c}\text { OW \& obese } \\
(n=10)\end{array}$ & $\begin{array}{c}\text { Control } \\
(n=10)\end{array}$ & $\begin{array}{c}\text { OW \& obese } \\
(\mathbf{n}=10)\end{array}$ & $\begin{array}{c}\text { Control } \\
(\mathbf{n}=10)\end{array}$ & $\begin{array}{c}\text { OW \& obese } \\
(\mathrm{n}=\mathbf{1 0})\end{array}$ \\
\hline \multicolumn{9}{|l|}{$\overline{\text { Before Ex (mg/l) }}$} \\
\hline Min. - Max. & $0.39-3.91$ & $1.08-6.73$ & $0.61-2.80$ & $1.58-4.32$ & $0.39-3.91$ & $1.08-6.73$ & $0.50-2.96$ & $1.35-4.90$ \\
\hline Median & 0.93 & 3.47 & 1.20 & 2.39 & 1.04 & 3.82 & 0.74 & 3.82 \\
\hline Sig. bet. $\operatorname{groups}(\mathrm{p})$ & \multicolumn{2}{|c|}{$<0.001^{*}$} & \multicolumn{2}{|c|}{$0.028^{*}$} & \multicolumn{2}{|c|}{$0.007^{*}$} & \multicolumn{2}{|c|}{$0.001^{*}$} \\
\hline \multicolumn{9}{|l|}{ After Ex (mg/l) } \\
\hline Min. - Max. & $0.52-3.96$ & $1.51-7.06$ & $0.63-3.0$ & $1.90-4.23$ & $0.53-3.96$ & $1.51-7.06$ & $0.52-2.97$ & $2.10-5.74$ \\
\hline Median & 1.01 & 3.59 & 1.55 & 2.71 & 1.06 & 4.03 & 0.74 & 4.30 \\
\hline Sig. bet. $\operatorname{groups}(\mathrm{p})$ & \multicolumn{2}{|c|}{$<0.001^{*}$} & \multicolumn{2}{|c|}{$0.019^{*}$} & \multicolumn{2}{|c|}{$0.003^{*}$} & \multicolumn{2}{|c|}{$0.001^{*}$} \\
\hline $\mathbf{p}_{1}$ & 0.087 & $<0.001^{*}$ & 0.506 & 0.386 & 0.241 & $0.005^{*}$ & 0.215 & $0.005^{*}$ \\
\hline \multicolumn{9}{|l|}{ Percent of change } \\
\hline Min. - Max. & $-22.06-64.10$ & $-9.09-56.25$ & $-21.43-36.36$ & $-9.09-33.54$ & $-22.06-64.10$ & $3.18-39.81$ & $-5.48-7.41$ & $7.8-56.25$ \\
\hline Median & 4.33 & 12.45 & 3.23 & 4.55 & 8.38 & 13.41 & 2.30 & 17.09 \\
\hline Sig. bet. groups (p) & \multicolumn{2}{|c|}{$0.013^{*}$} & \multicolumn{2}{|c|}{0.940} & \multicolumn{2}{|c|}{0.257} & \multicolumn{2}{|c|}{$<0.001^{*}$} \\
\hline
\end{tabular}

Note: Sig. bet. groups was done using Mann Whitney test for comparing between cases and control in each subgroup. $\mathrm{p}_{1}, \mathrm{p}$ value for Wilcoxon signed ranks test for comparing between baseline and after exercise; *statistically significant at $\mathrm{p} \leq 0.05$.

Table (3): Interleukin-6 (IL-6) level in control and overweight (OW) \& obese subjects in different groups of exercise intensity.

\begin{tabular}{|c|c|c|c|c|c|c|c|c|}
\hline \multirow[b]{2}{*}{ IL6 } & \multicolumn{2}{|c|}{ Total } & \multicolumn{2}{|c|}{ Low intensity exercise } & \multicolumn{2}{|c|}{$\begin{array}{l}\text { Moderate intensity } \\
\text { exercise }\end{array}$} & \multicolumn{2}{|c|}{ High intensity exercise } \\
\hline & $\begin{array}{c}\text { Control } \\
(n=30)\end{array}$ & $\begin{array}{c}\text { OW \& obese } \\
(n=30)\end{array}$ & $\begin{array}{c}\text { Control } \\
(n=10)\end{array}$ & $\begin{array}{c}\text { OW \& obese } \\
(n=10)\end{array}$ & $\begin{array}{l}\text { Control } \\
(n=10)\end{array}$ & $\begin{array}{c}\text { OW \& } \\
\text { obese } \\
(n=10)\end{array}$ & $\begin{array}{l}\text { Control } \\
(n=10)\end{array}$ & $\begin{array}{c}\text { OW \& obese } \\
(n=10)\end{array}$ \\
\hline \multicolumn{9}{|l|}{ Before $\operatorname{Ex}(\mathrm{Pg} / \mathrm{ml})$} \\
\hline Min. - Max. & $0.16-1.80$ & $0.50-5.12$ & $0.16-0.62$ & $0.80-5.12$ & $0.25-1.56$ & $0.91-3.41$ & $0.41-1.80$ & $0.50-2.85$ \\
\hline Median & 0.58 & 1.15 & 0.40 & 1.35 & 0.59 & 1.05 & 0.70 & 1.67 \\
\hline Sig. bet. groups (p) & \multicolumn{2}{|c|}{$<0.001^{*}$} & \multicolumn{2}{|c|}{$<0.001^{*}$} & \multicolumn{2}{|c|}{$0.019^{*}$} & \multirow{2}{*}{\multicolumn{2}{|c|}{$0.034^{*}$}} \\
\hline After Ex (Pg/ml) & & & & & & & & \\
\hline Min. - Max. & $0.17-2.18$ & $1.05-5.89$ & $0.17-0.74$ & $1.05-4.56$ & $0.46-1.93$ & $1.20-4.83$ & $0.48-2.18$ & $1.21-5.89$ \\
\hline Median & 0.67 & 2.40 & 0.47 & 2.42 & 0.68 & 2.0 & 0.84 & 3.32 \\
\hline Sig. bet. groups (p) & \multicolumn{2}{|c|}{$<0.001^{*}$} & \multicolumn{2}{|c|}{$<0.001^{*}$} & \multicolumn{2}{|c|}{$0.001^{*}$} & \multicolumn{2}{|c|}{$0.001^{*}$} \\
\hline $\begin{array}{c}p_{1} \\
\text { Percent of change }\end{array}$ & $<0.001^{*}$ & $<0.001^{*}$ & 0.059 & 0.069 & $0.047^{*}$ & $0.005^{*}$ & $0.005^{*}$ & $0.005^{*}$ \\
\hline Min. - Max. & $-33.66-230.0$ & $-10.94-180.81$ & $-13.79-230$ & $-10.94-180.81$ & $-33.66-84.0$ & $17.65-98.0$ & $10.0-36.25$ & $87.8-165.71$ \\
\hline Median & 19.30 & 89.62 & 22.01 & 17.92 & 19.20 & 42.16 & 17.49 & 104.85 \\
\hline Sig. bet. groups (p) & \multicolumn{2}{|c|}{$<0.001^{*}$} & \multicolumn{2}{|c|}{0.705} & \multicolumn{2}{|c|}{$0.005^{*}$} & \multicolumn{2}{|c|}{$<0.001^{*}$} \\
\hline
\end{tabular}

Note: Sig. bet. groups was done using Mann Whitney test for comparing between cases and control in each subgroup. $\mathrm{p}_{1}, \mathrm{p}$ value for Wilcoxon signed ranks test for comparing between baseline and after exercise; * statistically significant at $\mathrm{p} \leq 0.05$.

TNF- $\alpha$ level was significantly higher in the OW and obese subjects when compared with the control subjects in the total group as well as in the low intensity exercise subgroup, before and after exercise. However, in the moderate intensity exercise subgroup, the increase in levels of TNF- $\alpha$ in OW and obese individuals, compared with control subjects, did not reach the level of 
significance whether before or after exercise. In the high intensity exercise subgroup, TNF- $\alpha$ level was significantly higher in the OW and obese subjects when compared with the control subjects, only before exercise. TNF- $\alpha$ level decreased significantly following exercise in the $\mathrm{OW}$ and obese subjects in the total OW and obese group and in the moderate and high intensity exercise subgroups; however, the decrease was not significant in the low intensity exercise subgroup (table 4). The percent of change in TNF- $\alpha$ levels didn't differ significantly with increasing exercise intensity in the OW and obese subjects or in the control subjects (table 5).

Table (4): Tumor necrosis factor alpha (TNF- $\alpha$ ) level in control and overweight (OW) \& obese subjects in different groups of exercise intensity.

\begin{tabular}{|c|c|c|c|c|c|c|c|c|}
\hline \multirow[b]{2}{*}{ TNF- $\alpha$} & \multicolumn{2}{|c|}{ Total } & \multicolumn{2}{|c|}{ Low intensity exercise } & \multicolumn{2}{|c|}{ Moderate intensity exercise } & \multicolumn{2}{|c|}{ High intensity exercise } \\
\hline & $\begin{array}{l}\text { Control } \\
(n=30)\end{array}$ & $\begin{array}{c}\text { OW \& obese } \\
(n=30)\end{array}$ & $\begin{array}{c}\text { Control } \\
(n=10)\end{array}$ & $\begin{array}{c}\text { OW\& obese } \\
(n=10)\end{array}$ & $\begin{array}{c}\text { Control } \\
(n=10)\end{array}$ & $\begin{array}{c}\text { OW\& obese } \\
\quad(n=10)\end{array}$ & $\begin{array}{c}\text { Control } \\
(n=10)\end{array}$ & $\begin{array}{c}\text { OW \& } \\
\text { obese } \\
(\mathrm{n}=10)\end{array}$ \\
\hline \multicolumn{9}{|l|}{ Before Ex (Pg/ml) } \\
\hline Min. - Max. & $0.32-3.82$ & $0.47-4.55$ & $0.54-3.82$ & $1.33-4.55$ & $0.53-2.81$ & $0.74-1.32$ & $0.32-1.69$ & $0.47-1.83$ \\
\hline Median & 0.98 & 1.52 & 1.86 & 2.78 & 0.84 & 0.97 & 1.01 & 1.55 \\
\hline Sig. bet. groups $(p)$ & \multicolumn{2}{|c|}{$0.039^{*}$} & \multicolumn{2}{|c|}{$0.049^{*}$} & \multicolumn{2}{|c|}{0.545} & \multicolumn{2}{|c|}{$0.016^{*}$} \\
\hline \multicolumn{9}{|l|}{ After Ex (Pg/ml) } \\
\hline Min. - Max. & $0.25-4.02$ & $0.58-4.90$ & $0.46-4.02$ & $1.10-4.90$ & $0.58-2.72$ & $0.58-1.17$ & $0.25-1.65$ & $0.63-1.72$ \\
\hline Median & 0.80 & 1.23 & 1.59 & 2.59 & 0.79 & 0.83 & 0.78 & 1.26 \\
\hline Sig. bet. $\operatorname{groups}(\mathrm{p})$ & \multicolumn{2}{|c|}{$0.048^{*}$} & \multicolumn{2}{|c|}{$0.049^{*}$} & \multicolumn{2}{|c|}{0.880} & \multicolumn{2}{|c|}{0.075} \\
\hline $\begin{array}{c}\mathrm{p}_{1} \\
\text { Percent of change }\end{array}$ & $0.005^{*}$ & $0.001^{*}$ & 0.059 & 0.414 & 0.168 & $0.005^{*}$ & 0.126 & $0.012^{*}$ \\
\hline Min. - Max. & $-34.29-26.67$ & $-26.5-34.04$ & $-17.02-14.86$ & $-17.29-10.68$ & $-24.53-26.67$ & $-21.62--3.66$ & $-34.29-13.27$ & $-26.5-34.04$ \\
\hline Median & -12.29 & -10.97 & -13.07 & -4.48 & -3.98 & -11.80 & -21.19 & -14.0 \\
\hline Sig. bet. groups $(p)$ & \multicolumn{2}{|c|}{0.802} & \multicolumn{2}{|c|}{0.174} & \multicolumn{2}{|c|}{0.174} & \multicolumn{2}{|c|}{0.364} \\
\hline
\end{tabular}

Note: Sig. bet. groups was done using Mann Whitney test for comparing between cases and control in each subgroup. $p_{1}, p$ value for Wilcoxon signed ranks test for comparing between baseline and after exercise; *statistically significant at $\mathrm{p} \leq 0.05$.

Table (5): Effect of different exercise intensities on C-reactive protein (CRP), Interlukin-6 (IL-6) and Tumor necrosis factor alpha (TNF- $\alpha$ ) levels in the control subjects and in the overweight and obese subjects.

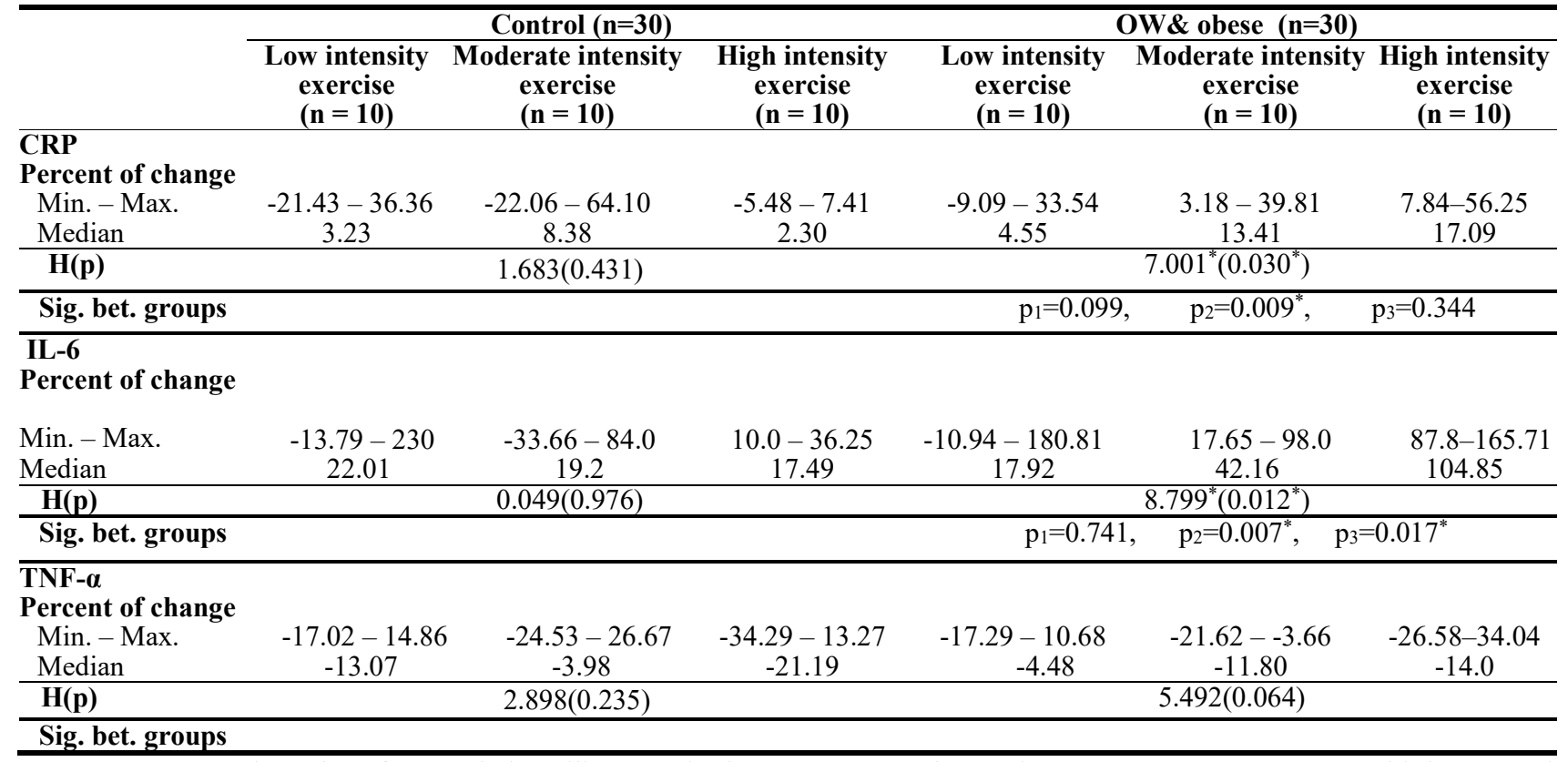

Note: $\mathrm{H}, \mathrm{p}, \mathrm{H}$ and $\mathrm{p}$ values for Kruskal Wallis test; Sig. bet. groups was done using Post Hoc Test (Dunn's multiple comparisons test); $\mathrm{p}_{1}, \mathrm{p}$ value for comparing between low and moderate exercise intensities; $\mathrm{p}_{2}, \mathrm{p}$ value for comparing between low and high exercise intensities; $\mathrm{p}_{3}, \mathrm{p}$ value for comparing between moderate and high exercise intensities; *statistically significant at $\mathrm{p} \leq 0.05$. 
Correlation studies: In the total OW and obese group, the percent of increase in IL-6 levels following exercise correlated positively with each of the following: percent of increase in CRP levels ( $r=0.57, \mathrm{p}=0.001)$, fig.(1) and percent of decrease in TNF- $\alpha$ levels $(r=0.394, p=0.031)$.
Also, the percent of increase in IL-6 levels following exercise correlated positively with the percent of decrease in TNF- $\alpha$ levels in the OW and obese moderate $(\mathrm{r}=0.782, \mathrm{p}=0.008)$ and high $(\mathrm{r}=0.648$, $\mathrm{p}=0.003)$ intensity exercise subgroups, figs. $(2,3)$.

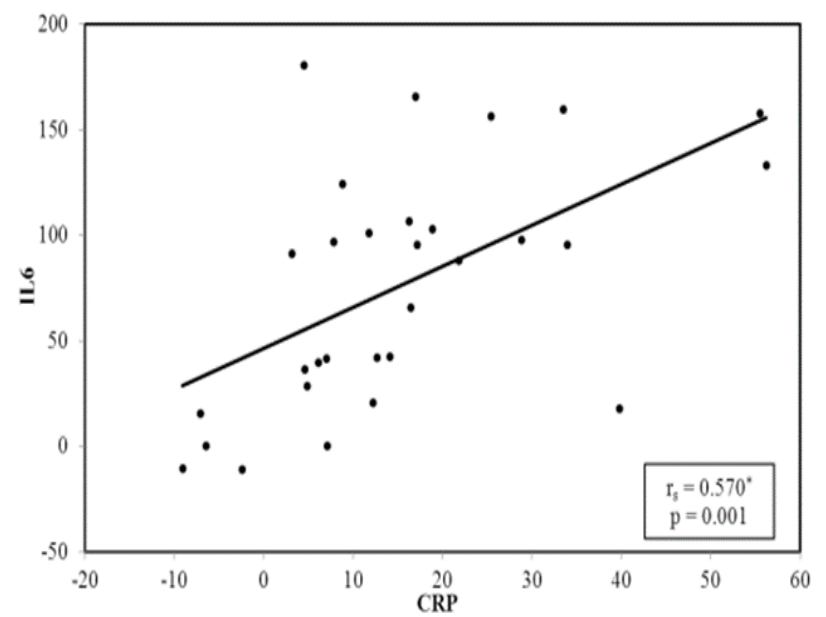

Figure (1): Correlation between percent of increase of C-reactive protein (CRP) and percent of increase of intelukin-6 (IL-6) following exercise in total OW \& obese group.

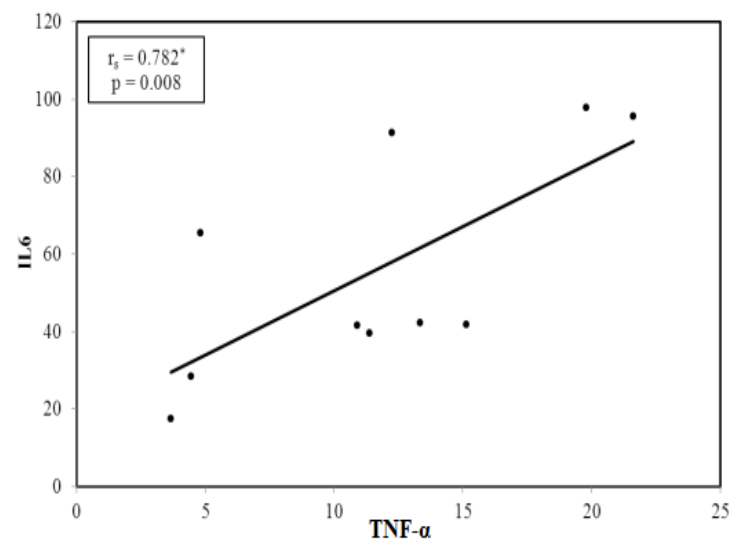

Figure (2): Correlation between percent of decrease of tumor necrosis factor alpha (TNF- $\alpha$ ) and percent of increase of intelukin-6 (IL-6) following exercise in OW \& obese moderate intensity exercise subgroup.

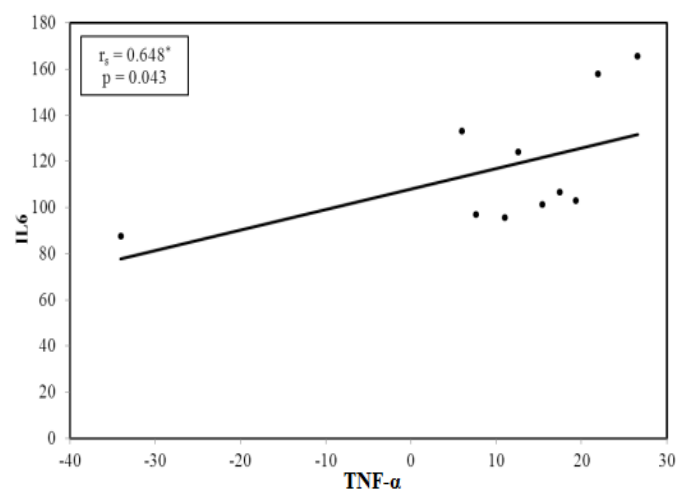

Figure (3): Correlation between percent of decrease of tumor necrosis factor alpha (TNF- $\alpha$ ) and percent of increase of intelukin-6 (IL-6) following exercise in OW \& obese high intensity exercise subgroup. 


\section{Discussion}

Regular exercise training has been reported to decrease chronic inflammation [22]. The long-term effect of exercise training in protection against diseases associated with chronic low-grade inflammation may be attributed to the antiinflammatory response elicited by repeated bouts of acute exercise [12,22].

However, most of the researches on exercisederived inflammatory markers have primarily been performed in young lean subjects leaving the question of the impact of obesity unanswered [23]. Additionally, some of the studies investigating acute moderate intensity exercise have reported significant changes in certain inflammatory markers [16,24], while others [14, 25] reported no detectable effect on markers of inflammation.

In the present study, the total OW and obese group exhibited significantly higher basal serum levels of CRP, IL- 6 and TNF- $\alpha$, when compared with the total control group. Following an acute bout of moderate or high intensity exercise, OW and obese subjects showed significant increase in CRP and IL-6 levels; however, TNF- $\alpha$ levels significantly decreased. Nevertheless, an acute low intensity exercise induced no significant changes in any of the measured inflammatory markers in the OW and obese subjects.

Our findings are consistent with findings of other investigators [26,27] who demonstrated significantly higher levels of CRP, TNF- $\alpha$ and IL6 in obese subjects in comparison to lean subjects. The main source for the increased production of TNF- $\alpha$ and IL- 6 in obesity is adipose tissue macrophages (ATMs), other sources include adipocytes and pre-adipocytes [28]. IL-6 in turn increases the hepatic production of CRP [29].
In the current study, CRP levels increased significantly following a 20 minutes incremental exercise session in the OW and obese subjects who performed moderate (at $60 \%$ of age predicted maximum heart rate) and high (at $80 \%$ of age predicted maximum heart rate) intensity exercise. CRP levels did not significantly increase in OW and obese subjects who performed low (at $45 \%$ of age predicted maximum heart rate) intensity exercise. These findings are consistent with Mendham et al. [15] who found a higher CRP response following 40 minutes moderate-vigorous exercise protocol in comparison to low-intensity protocol in sedentary overweight subjects. In contrast, Makrovitch et al. [14] reported that treadmill walking at a moderate intensity for 30 minutes did not change CRP concentrations in overweight middle-aged men (mean BMI $28 \pm 3$ $\mathrm{kg} / \mathrm{m}^{2}$ ). This discrepancy could be explained by differences in subjects' characteristics such as the degree of obesity and BMI.

Our observation that the rise in CRP concentrations increased significantly with increasing exercise intensity from low to high intensity in the OW and obese subjects, can be explained by CRP production associated with exercise-induced muscle damage and subsequent repair [30]. BMI was found to be one of the potential factors related to the extent of muscle damage after exercise [31].

In the present study, there was a significant positive correlation between the percent of increase of IL- 6 and the percent of increase of CRP in the total OW and obese group, which can be explained by the role of IL- 6 in stimulating CRP production from the liver [29]. 
In the present study, we found a significant increase in IL-6 levels in the OW and obese subjects following an acute bout of moderate and high intensity exercise. However, IL-6 levels didn't significantly increase in OW and obese subjects who performed low intensity exercise.

Our findings agree with the results of previous studies $[13,32,33]$ in which IL-6 appears to be the cytokine most consistently elevated in response to exercise. Hojbjerre et al. [13] reported that one hour of exercise at $55 \%$ of $\mathrm{VO}_{2 \max }$ increased the plasma IL-6 concentration and the increase tended to be higher in overweight than in lean subjects. Gökbel et al. [32] also concluded that plasma IL-6 levels significantly increased following supramaximal exercise compared with preexercise.

Monocytes are not major contributors to the IL-6 response to exercise [34]. The major source for the exercise-related IL-6 increase is the skeletal muscle [35]. Small amounts of IL-6 are also produced and released from adipose tissue [36]. The peritendon tissue may release IL- 6 in response to exercise as well [37]. Although the biological action of muscle-derived IL- 6 has not been determined, increasing data suggest that the role of IL-6 released from contracting muscle during exercise is to act in a hormone like manner to induce mobilization of extracellular substrates and/or augmentation of substrate delivery during exercise [38,39]. Moreover, IL-6 stimulates lipolysis as well as fat oxidation [40].

Our results also showed that the rise in IL-6 levels increased with increasing exercise intensity from low to moderate to high intensity in the OW and obese subjects. This is probably a result of increased muscle damage, as IL-6 has been shown to be correlated with markers of muscle damage, most importantly creatine kinase (CK) [41] that has been demonstrated to be significantly higher in the high BMI subjects than in the normal BMI subjects following exercise [31]. IL-6 is believed to play an important mediatory role in the inflammatory response needed for the exerciseassociated muscle damage repair [42]. Additionally, the exercise-induced increase in plasma IL-6 may be related to some extent to the sympatho-adrenal response to exercise [43]. This may explain the intensity dependent increase in IL6 following exercise.

On the other hand, we observed a modest, though significant, decrease in TNF- $\alpha$ levels following an acute bout of exercise among the OW and obese subjects in the moderate and high intensity exercise subgroups. However, the decrease in TNF- $\alpha$ levels didn't reach the level of significance in the OW and obese subjects who performed low intensity exercise.

In accordance with our findings, Hirose et al. [44] reported a significant decrease in TNF- $\alpha$ levels following a single bout of eccentric exercise. On the other hand, findings from the work carried out by Hojbjerre et al. [13] revealed that one hour of exercise at $55 \%$ of $\mathrm{VO}_{2 \max }$ did not change the plasma TNF- $\alpha$ concentration in either overweight or lean subjects. Similarly, another study by Gökbel et al. [32] concluded that plasma TNF- $\alpha$ levels did not change with supramaximal exercise compared with pre-exercise.

Several factors could account for the inconsistency of results between different studies including difference in subjects' characteristics (age, bodyweight, individual level of cardiorespiratory fitness), exercise intensity and 
duration, exercise type, and timing of blood sampling.

In the present study, we observed a significant positive correlation between the percent of increase of IL-6 and the percent of decrease of TNF- $\alpha$ in the OW and obese moderate and high intensity exercise subgroups and total OW and obese group. Hence, the observed decrease in TNF- $\alpha$ levels may be the result of the inhibitory role of IL-6, since it has been demonstrated that IL-6 inhibits TNF- $\alpha$ production [41]. The suppression of TNF- $\alpha$ following exercise is likely also via IL-6 independent pathways. High levels of epinephrine are provoked by exercise, and epinephrine has been shown to suppress monocyte TNF- $\alpha$ production via $\beta 2$ adrenergic receptors (ARs) dependent mechanism [45].

High serum TNF- $\alpha$ levels are associated with insulin resistance as a result of impaired insulin signaling [46]. TNF- $\alpha$ has also been shown to negatively regulate adiponectin production and secretion from adipocytes [47]. Adiponectin plays a role in increasing insulin sensitivity via suppression of gluconeogenesis and regulation of fatty acid metabolism [48]. Since insulin sensitivity improves with both acute and chronic exercise training [49], it is reasonable to assume that the exercise-induced decrease in TNF- $\alpha$ may play a role in modifying insulin sensitivity following a single exercise session.

In conclusion, our results suggest that an acute bout of moderate or high intensity exercise, but not low intensity exercise, induces an inflammatory response characterized by a rise in the levels of CRP and IL- 6 , and a decrease in the level of TNF- $\alpha$ in overweight and obese subjects. Thus, it seems that exercise intensity is a determining factor for the inflammatory response to an acute bout of exercise in overweight and obese subjects, with some sort of intensity threshold that must be reached to provoke a detectable change in various makers of inflammation. One potential limitation in the present study is the small sample size per group, which can't be excluded as a reason for the inability to detect significant differences in the levels of the inflammatory markers in the overweight and obese subjects following low intensity exercise. Further research using a larger sample size is recommended in order to increase the statistical power for investigating the effect of an acute bout of low intensity exercise on the inflammatory markers in overweight and obese subjects.

\section{References}

1. World Health Organization. 2018. Obesity and overweight. Fact sheet No 311. Last accessed at:

http://www.who.int/mediacentre/factsheets/fs3 11/en/index.html, 6 January 2020.

2. Rodríguez-Hernández $\mathbf{H}$, Simental-Mendía L, Rodríguez-Ramírez G, Reyes-Romero M. Obesity and inflammation: Epidemiology, risk factors, and markers of inflammation. Int $J$ Endocrinol 2013: 678159, 2013. doi: 10.1155/2013/678159.

3. Cottam DR, Mattar SG, Barinas-Mitchell E, Eid G, Kuller L, Kelley DE, Schauer PR. The chronic inflammatory hypothesis for the morbidity associated with morbid obesity: Implications and effects of weight loss. Obes Surg 14: 589-600, 2004.

4. Berg AH, Scherer PE. Adipose tissue, inflammation, and cardiovascular disease. Circ Res 96: 939-949, 2005.

5. Bruun JM, Helge JW, Richelsen B, Stallknecht B. Diet and exercise reduce lowgrade inflammation and macrophage 
infiltration in adipose tissue but not in skeletal muscle in severely obese subjects. Am $J$ Physiol Endocrinol Metab 290: 961-967, 2006.

6. Imayama I, Ulrich CM, Alfano CM, Wang C, Xiao L, Wener MH, Campbell KL, Duggan C, Foster-Schubert KE, Kong A, Mason CE, Wang CY, Blackburn GL, Bain CE, Thompson HJ, McTiernan A. Effects of a caloric restriction weight loss diet and exercise on inflammatory biomarkers in overweight/obese postmenopausal women: A randomized controlled trial. Cancer Res 72: 2314-2326, 2012.

7. Shaw KA, Gennat HC, O'Rourke P, Del Mar C. Exercise for overweight or obesity. Cochrane Database of Systematic Reviews 4: CD003817, $2006 . \quad$ doi: 10.1002/14651858.CD003817.pub3.

8. Nicklas BJ, Hsu FC, Brinkley TG, Church T, Goodpaster BH, Kritchevsky SB, Pahor M. Exercise training and plasma C-reactive protein and interlukin-6 in the elderly. $J \mathrm{Am}$ Geriatr Soc 56: 2045-2052, 2008.

9. Hayashino $\mathrm{Y}$, Jackson JL, Hirata T, Fukumori N, Nakamura F, Fukuhara S, Tsujii S, Ishii H. Effects of exercise on C-reactive protein, inflammatory cytokine and adipokine in patients with type 2 diabetes: a meta-analysis of randomized controlled trials. Metabolism 63(3): 431-440, 2014.

10. O'Leary VB, Marchetti CM, Krishnan RK, Stetzer BP, Gonzalez F, Kirwan JP. Exercise-induced reversal of insulin resistance in obese elderly is associated with reduced visceral fat. J Appl Physiol 100:1584-1589, 2006.

11. Ho SS, Dhaliwal SS, Hills AP, Pal S. Effects of chronic exercise training on inflammatory markers in Australian overweight and obese individuals in a randomized controlled trial. Inflammation 36: 625-632, 2013.
12. Petersen AM, Pedersen BK. The antiinflammatory effect of exercise. $J$ Appl Physiol 98:1154-1162, 2005.

13. Hojbjerre L, Rosenzweig M, Dela F, Bruun JM , Stallknecht B. Acute exercise increases adipose tissue interstitial adiponectin concentration in healthy overweight and lean subjects. Eur J Endocrinol 157: 613-623, 2007.

14. Markovitch D, Tyrell RM, Thompson D. Acute moderate-intensity exercise in middleaged men has neither an anti- nor proinflammatory effect. $J$ Appl Physiol 105: 260-265, 2008.

15. Mendham AE, Donges CE, Liberts EA, Duffield R. Effects of mode and intensity on the acute exercise-induced IL- 6 and CRP responses in a sedentary, overweight population. Eur J Appl Physiol 111:10351045, 2011.

16. Christiansen T, Bruun JM, Paulsen SK, Olholm J, Overgaard K, Pedersen SP, Richelsen B. Acute exercise increases circulating inflammatory markers in overweight and obese compared with lean subjects. Eur J Appl Physiol 113: 1635-1642, 2013.

17. Kujala UM. Evidence on the effects of exercise therapy in the treatment of chronic disease. Br J Sports Med 43: 550-555, 2009.

18. World Health Organization. 2008. Waist Circumference and Waist-Hip Ratio: Report of a WHO Expert Consultation. World Health Organization, Geneva, Switzerland.

19. Pollock ML, Gaesser GA, Butcher JD, Després JP, Dishman RK, Franklin BA, Garber CE. The recommended quantity and quality of exercise for developing and maintaining cardiorespiratory and muscular fitness, and flexibility in healthy adults. Med Sci Sports Exerc 30: 975-991, 1998. 
20. Robergs RA. Simplified method and program for incremental exercise protocol development. J Exerc Physiol 10:1-23, 2007.

21. Park HS, Park JY, Yu R. Relationship of obesity and visceral adiposity with serum concentrations of CRP, TNF- $\alpha$ and IL-6. Diabetes Res Clin Pract 69:29-35, 2005.

22. Pedersen BK. The anti-inflammatory effect of exercise: its role in diabetes and cardiovascular disease control. Essays Biochem 42: 105-117, 2006.

23. Brown WM, Davison GW, McClean CM, Murphy MH. A systematic review of the acute effects of exercise on immune and inflammatory indices in untrained adults. Sports Med Open 1(1): 35, 2015.

24. Shojaei EA, Farajov A, Jafari A. Effect of moderate aerobic cycling on some systemic inflammatory markers in healthy active collegiate men. Int J Gen Med 4:79-84, 2011.

25. Plaisance EP, Taylor JK, Alhassan S, Abebe A, Mestek ML, Grandjean PW. Cardiovascular fitness and vascular inflammatory markers after acute aerobic exercise. Int J Sport Nutr Exerc Metab 17(2): 152-162, 2007.

26. Popko K, Gorska E, Stelmaszczyk-Emmel A, Plywaczewski R, Stoklosa A, Gorecka D, Pyrzak B, Demkow U. Proinflammatory cytokines Il- 6 and TNF- $\alpha$ and the development of inflammation in obese subjects. Eur J Med Res 15: 120-122, 2010.

27. Derosa G, Fogari E, D'Angelo A, Bianchi L, Bonaventura A, Romano D, Maffioli P. Adipocytokine levels in obese and non-obese subjects: an observational study. Inflammation 36(4): 914-920, 2013.

28. Sun S, Ji Y, Kersten S, Qi L. Mechanisms of inflammatory responses in obese adipose tissue. Ann Rev Nutr 32: 261-286, 2012.

29. Tanaka T, Narazaki M, Kishimoto T. IL-6 in inflammation, immunity, and disease. Cold
Spring Harb Perspect Biol. 6(10): a016295, 2014. doi:10.1101/cshperspect.a016295

30. Neubauer O, Koenig D, Wagner KH. Recovery after an Ironman triathlon: sustained inflammatory responses and muscular stress. Eur J Appl Physiol 104(3): 417-426, 2008.

31. Kim J, So WY. High body mass index is associated with the extent of muscle damage after eccentric exercise. Int $J$ Environ Res Public Health 15(7): 1378, 2018. doi:10.3390/ijerph15071378.

32. Gökbel H, Okudan N, Gül I, Belviranli M, Gergerlioğlu HS, Başaral MK. Effects of repeated bouts of supramaximal exercise on plasma adiponectin, interleukin-6, and tumor necrosis factor- $\alpha$ levels in sedentary men. $J$ Strength Cond Res 26(6): 1675-1679, 2012.

33. Almada C, Cataldo LR, Smalley SV, Diaz E, Serrano A, Hodgson MI, Santos JL. Plasma levels of interleukin-6 and interleukin18 after an acute physical exercise: relation with post-exercise energy intake in twins. $J$ Physiol Biochem 69(1): 85-95, 2013.

34. Starkie RL, Rolland J, Angus DJ, Anderson MJ, Febbraio MA. Circulating monocytes are not the source of elevations in plasma IL-6 and TNF- levels after prolonged running. Am J Physiol Cell Physiol 280: 769-774, 2001.

35. Pedersen BK, Febbraio MA. Muscle as an endocrine organ: focus on muscle-derived interleukin-6. Physiol Rev 88: 1379-1406, 2008.

36. Lyngsø D, Simonsen L, Bülow J. Interleukin6 production in human subcutaneous abdominal adipose tissue: the effect of exercise. J Physiol. 15: 373-378, 2002.

37. Langberg H, Olesen JL, Gemmer C, Kjaer M. Substantial elevation of interleukin-6 concentration in peritendinous tissue, in contrast to muscle, following prolonged exercise in humans. J Physiol 542: 985-990, 2002. 
38. Fischer CP. Interleukin-6 in acute exercise and training: what is the biological relevance? Exerc Immunol Rev 12: 6-33, 2006.

39. Mathur M, Pedersen BK. Exercise as a mean to control low-grade inflammation. Mediators Inflamm, 2008. doi:10.1155/2008/109502

40. van Hall G, Steensberg A, Sacchetti M, Fischer C, Keller C, Schjerling P, Hiscock N, Møller K, Saltin B, Febbraio MA, Pedersen BK. Interleukin-6 stimulates lipolysis and fat oxidation in humans. $J$ Clin Endocrinol Metab 88: 3005-3010, 2003.

41. Toft AD, Jensen LB, Bruunsgaard H, Ibfelt T, Halkjaer-Kristensen J, Febbraio M, Pedersen BK. Cytokine response to eccentric exercise in young and elderly humans. $\mathrm{Am} J$ Physiol 283: 289-295, 2002.

42. Pedersen BK, Steensberg A, Fischer C, Keller C, Keller P, Plomgaard P, WolskPetersen E, Febbraio M. The metabolic role of IL-6 produced during exercise: Is IL- 6 an exercise factor? Proc Nutr Soc 63: 263-267, 2004.

43. Pedersen BK, Steensberg A, Fischer C, Keller C, Keller P, Plomgaard P, Febbraio M, Saltin B. Searching for the exercise factor: is IL-6 a candidate? $J$ Muscle Res Cell Motil 24:113-119, 2003.

44. Hirose L, Nosaka K, Newton M, Laveder A, Kano M, Peake J, Suzuki K. Changes in inflammatory mediators following eccentric exercise of the elbow flexors. Exerc Immunol Rev 10: 75-90, 2004.

45. Dimitrov S, Hulteng E, Hong S. Inflammation and exercise: Inhibition of monocytic intracellular TNF production by acute exercise via $\beta 2$-adrenergic activation. Brain Behav Immun 61: 60-68, 2017.

46. Plomgaard P, Bouzakri K, Krogh-Madsen R, Mittendorfer B, Zierath J. R, Pedersen B K. Tumor necrosis factor-alpha induces skeletal muscle insulin resistance in healthy human subjects via inhibition of Akt substrate 160 phosphorylation. Diabetes 54: 2939-2945, 2005.

47. Hector J, Schwarzloh B, Goehring J, Strate TG, Hess UF, Deuretzbacher G, HansenAlgenstaedt $\mathbf{N}$, Beil FU, Algenstaedt $P$. TNF- $\alpha$ alters visfatin and adiponectin levels in human fat. Horm Metab Res 39: 250-255, 2007.

48. Stern JH, Rutkowski JM, Scherer PE. Adiponectin, leptin, and fatty acids in the maintenance of metabolic homeostasis through adipose tissue crosstalk. Cell Metab 23(5): 770-784, 2016.

49. Henriksen E. Invited Review: Exercise effects of muscle insulin signaling and action, Invited review: effects of acute exercise and exercise training on insulin resistance. $J$ Appl Physiol 93: 788-796, 2002. 